\title{
Ultrasensitive Nano-ELISA for Detecting Sulfadimethoxine in Chicken Tissue
}

\author{
Chi-Fang Peng, ${ }^{1}$ Xiao-Hui Duan, ${ }^{1}$ Qiu-Li Pan, ${ }^{1}$ Li-Qiang Liu, ${ }^{1}$ and Feng Xue ${ }^{2}$ \\ ${ }^{1}$ State Key Lab of Food Science and Technology, School of Food Science and Technology, Jiangnan University, Wuxi 214122, China \\ ${ }^{2}$ Animal, Plant \& Food Inspection Center, Jiangsu Entry-Exit Inspection and Quarantine Bureau, Nanjing 200001, China
}

Correspondence should be addressed to Chi-Fang Peng; pcf@jiangnan.edu.cn

Received 23 September 2013; Revised 3 December 2013; Accepted 8 December 2013

Academic Editor: Pranav S. Shrivastav

Copyright (C) 2013 Chi-Fang Peng et al. This is an open access article distributed under the Creative Commons Attribution License, which permits unrestricted use, distribution, and reproduction in any medium, provided the original work is properly cited.

It is challenging to obtain a highly sensitive enzyme-linked sorbent immunoassay (ELISA) method for the rapid screening of veterinary drug residue in animal tissues. Here we present that a simple and sensitive detection for sulfadimethoxine (SDM) residue in animal tissues was achieved by utilizing a bioconjugate of gold nanoparticles and enzyme-labeled antibody as signal probe in enzyme-linked sorbent immunoassay (ELISA). The developed nano-ELISA has increased the sensitivity of a traditional ELISA for SDM by 20 -fold. The sensitivity of this ELISA was $5 \mathrm{pg} / \mathrm{mL}$ in buffer, and the detection limit (LOD) of $0.2 \mu \mathrm{g} / \mathrm{kg}$ can be obtained after chicken liver was simply extracted by buffer. This simple and sensitive method can be used to improve the sensitivity of ELISA methods for various small molecule contaminants.

\section{Introduction}

Sulfonamides are widely used to treat bacterial and protozoan infections in food animals. Their pharmacological activity is due to their ability to mimic p-aminobenzoic acid (PABA) and to inhibit the early stages of folic acid synthesis in bacteria and in various protozoans [1]. However, sulfonamides can be accumulated in the body of people who consumed products from those excessively drug-treated animals, resulting in the development of antibiotic-resistant pathogenic bacteria. To minimize this risk, a maximum residue limit of $0.1 \mathrm{mg} \mathrm{kg}^{-1}$ has been established for total or individual sulfonamides in food samples, including meat and milk, by Codex Alimentarius Commission in European and American countries [2]. Sulfadimethoxine (SDM) is a typical example of sulfonamides which are widely used antibiotics worldwide. Many cases about administrating SDM excessively have been reported for the prevention and treatment of infections in chicken, swine, and cattle [2-5].

Conventional residue methods for the detection of sulfonamides in animal tissues include bioassays, thin layer chromatography (TLC), high-performance liquid chromatography (HPLC), and liquid chromatography-tandem mass spectrometry (LC-MS/MS) [1,5-8]. In an effort to increase both method sensitivity and sample throughput, enzyme-linked immunosorbent assays (ELISAs) have been developed for several of the sulfonamides [1,9-11]. Although high sensitivity has been achieved in the above-mentioned immunoassays, accomplishing the detection of veterinary drug residue in animal tissues simply and sensitively by ELISA method is still challenging due to serious matrix interference [12,13]. Nevertheless, developing highly sensitive ELISA method can avoid this problem by diluting the sample extract and decreasing the matrix interference obviously [12, 14-16].

Gold nanoparticles (GNPs) with outstanding characteristics have attracted great interest in biosensors recent years [17-20]. In this work, a novel nano-ELISA was used for rapid and sensitive detection of SDM, as a model compound for veterinary antibiotics. Scheme 1 that shows an immunereaction nanocomplex forms in the surface of microplate wells. Combing a traditional ELISA format and a GNPantibody-enzyme bioconjugate as label, this nano-ELISA can achieve very low detection limit of $0.2 \mathrm{ng} / \mathrm{g}$ SDM in chicken tissue by implementing as simply as the traditional ELISA.

\section{Experimental}

2.1. Chemicals and Reagents. Monoclonal mouse antibody against SDM was produced by immunizing balb/c mice with 


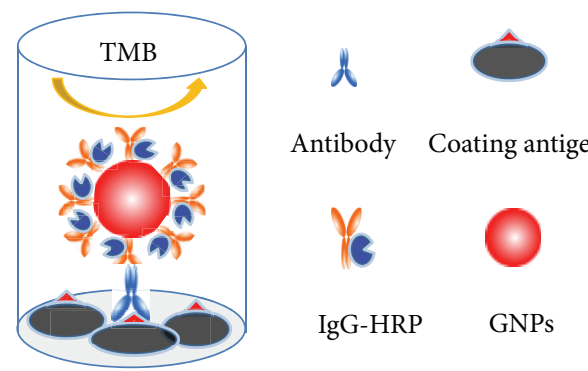

Scheme 1: The immune-reaction nanocomplex forms in the surface of microplate wells.

SDM-BSA and hybridoma cell cloning technique in our laboratory [21]. SDM was purchased from Aladin Regent (Shanghai). Ovalbumin (OVA), 3,3',5,5' -tetramethylbenzidine (TMB), chloroauric acid ( $\mathrm{HAuCl} 4)$, and trisodium citrate were purchased from Sigma-Aldrich (St. Louis, MO, USA). The peroxidase-conjugated goat anti-mouse IgG (IgGHRP) was purchased from Kangchen Biotechnology Company (Shanghai, China). Control chicken liver tissue was obtained from the Testing Center of Animals, Plants, and Food, Jiangsu Entry and Exit Inspection, and Quarantine Bureau. Microtiter plates were obtained from Costar Group, Inc. (Bethesda, MD, USA). Other chemical regents all were of analytical grade and from Shanghai Chemical Reagents Company (Shanghai, China). All buffers used in the experiments were prepared using Milli-Q water by Milli-Q system (Millipore, Bedford, MA).

2.2. Solutions and Buffers. Coating buffer, $50 \mathrm{mmol} / \mathrm{L}$ carbonate buffer ( $\mathrm{pH}$ 9.5); dilution buffer (phosphate buffered saline (PBS)), $10 \mathrm{mmol} / \mathrm{L}$ sodium phosphate buffer ( $\mathrm{pH} 7.4$ ) containing $140 \mathrm{mmol} / \mathrm{L} \mathrm{NaCl}$; washing buffer, PBS containing $0.05 \%(\mathrm{v} / \mathrm{v})$ Tween $20(\mathrm{PBST})$; TMB solution, $50 \mathrm{mmol} / \mathrm{L}$ sodium citrate buffer ( $\mathrm{pH} 5.0$ ) containing $0.01 \%(\mathrm{w} / \mathrm{v}) \mathrm{TMB}$, and $0.005 \%(\mathrm{v} / \mathrm{v}) \mathrm{H}_{2} \mathrm{O}_{2}$ were used.

2.3. Preparation of Conjugate of Hapten and Protein. The hapten of SDM and protein conjugate were prepared according to [1]. Briefly, $10 \mathrm{mg} \mathrm{SDM}$ was dissolved in warm $0.1 \mathrm{~N}$ sulfuric acid $\left(4 \mathrm{~mL}, 70^{\circ} \mathrm{C}\right)$. The solution was then cooled in an ice bath, and $1 \mathrm{~mL}$ of freshly prepared sodium nitrate $(19 \mathrm{mg} / \mathrm{mL})$ was added dropwise over $3 \mathrm{~min}$ and incubated for an additional $3 \mathrm{~min}$. A solution of OVA ( $100 \mathrm{mg}$ in $4 \mathrm{~mL}$ of $0.5 \mathrm{M}$ borate, $\mathrm{pH}$ 9.4) was cooled to $0^{\circ} \mathrm{C}$, and the diazotized hapten solution was added to the cooled OVA solution over a period of $15 \mathrm{~min}$. The $\mathrm{pH}$ of the solution was maintained between 9.0 and 9.5 using sodium hydroxide $(1 \mathrm{M})$. After $4 \mathrm{~h}$, the reaction mixture was stored at room temperature, exhaustively dialyzed against $10 \mathrm{mM}$ phosphate buffer, $\mathrm{pH} 7.2,(9 \times 2 \mathrm{~L})$ at $4^{\circ} \mathrm{C}$, and stored at $-20^{\circ} \mathrm{C}$ prior to use.

2.4. Synthesis and Characterization of Gold Nanoparticles. Gold nanoparticles (GNPs) $(15 \mathrm{~nm})$ were synthesized by reducing tetrachloroauric acid with trisodium citrate [22]. All glassware and magnetic stir bars used in the synthesis were thoroughly cleaned in aqua regia. $100 \mathrm{~mL}$ of $0.1 \% \mathrm{HAuCl}_{4}$ solution was boiled with vigorous stirring in a $250 \mathrm{~mL}$ roundbottom flask. Two $\mathrm{mL}$ of $1 \%$ trisodium citrate solution was then added quickly to the boiling solution resulting in a color change from pale yellow to dark red and indicating the formation of GNPs. The solution was maintained for $10 \mathrm{~min}$ at boiling temperature and then stirred to cool down. The synthesized GNPs were characterized using UV-vis spectroscopy (Figure 2) and dynamic laser scattering (DLS) (Figure 3) to analyze their size.

2.5. Preparation of the GNP-IgG-HRP Conjugate. The GNPsIgG-HRP conjugate was prepared as follow. Precisely, $1 \mathrm{~mL}$ of GNP $(15 \mathrm{~nm})$ solution was mixed with 1,2 , or $3 \mu \mathrm{L}$ of $\mathrm{K}_{2} \mathrm{CO}_{3}$ $(200 \mathrm{mM})$, and $100 \mu \mathrm{L}$ of IgG-HRP solution at a concentration of $100 \mu \mathrm{g} / \mathrm{mL}$ was added to $1 \mathrm{~mL}$ of the GNP solution. The mixture was stirred for $30 \mathrm{~min}$, and then it was centrifuged at $13000 \mathrm{rpm}$ for $15 \mathrm{~min}$ at $4^{\circ} \mathrm{C}$ to remove the excess of antibody. The clear supernatant was carefully removed, and the precipitated gold conjugates were resuspended in $1 \mathrm{~mL}$ of PBS buffer $(0.01 \mathrm{M}, \mathrm{pH} 7.4)$ and stored at $4^{\circ} \mathrm{C}$. The stabilities of these conjugates were evaluated by adding $100 \mathrm{uL}$ of $\mathrm{NaCl}$ (10\%) and keeping at $4^{\circ} \mathrm{C}$ for 24 hours to observe their color change. It was found that the conjugates prepared with adding 1-2 $\mu \mathrm{L}$ of $\mathrm{K}_{2} \mathrm{CO}_{3}$ appeared blue to some extent, while the conjugate prepared with adding $3 \mu \mathrm{L}$ of $\mathrm{K}_{2} \mathrm{CO}_{3}$ still appeared red. Finally, this conjugate, prepared with adding $3 \mu \mathrm{L}$ of $\mathrm{K}_{2} \mathrm{CO}_{3}$, was used for further application. The conjugate was also characterized using UV-vis spectroscopy (Figure 2) and DLS (Figure 3) to analyze the size.

2.6. Nano-ELISA. The protocol of the nano-ELISA was similar to traditional indirect ELISA method except that the IgG-HRP was replaced with the GNPs-IgG-HRP conjugate. The general procedure adopted to develop the assay was as follows. $100 \mu \mathrm{L}$ of SDM-OVA $(10 \mu \mathrm{g} / \mathrm{mL})$ was added to each well of 96-well microplate and immobilized overnight. Excess coating antigen was removed by decanting the plate content and washing the plate wells. The remaining sites in the well were blocked by incubating $200 \mu \mathrm{L}$ of blocking buffer ( $1 \%$ BSA in PBST) for $2 \mathrm{~h}$ at room temperature. After decanting blocking buffer and washing, $50 \mu \mathrm{L}$ of SDM standard solution and $50 \mu \mathrm{L}$ of anti-SDM antibody solution diluted by antibody dilution buffer (PBST containing $0.1 \%$ gelatin) were added to the wells and then incubated at $37^{\circ} \mathrm{C}$ for $30 \mathrm{~min}$. After the solution in wells was decanted and the wells were washed, $100 \mu \mathrm{L}$ of diluted GNPs-IgG-HRP conjugate was added to each well. After incubation for $30 \mathrm{~min}$, the wells were washed. HRP substrate, TMB and $\mathrm{H}_{2} \mathrm{O}_{2}$ solutions, were added and color was developed for $15 \mathrm{~min}$. Then the reaction was stopped by adding $2 \mathrm{M}$ sulfuric acid $(100 \mu \mathrm{L})$ to each well. The optical density was read at $450 \mathrm{~nm}$ with a microplate reader within $5 \mathrm{~min}$ after stopping the reaction.

2.7. Sample Pretreatment and Validation of the Nano-ELISA. The sample pretreatment method was slightly modified according to [7]. Control chicken liver tissues, confirmed without SDM contamination by LC-MS/MS, were cut up 


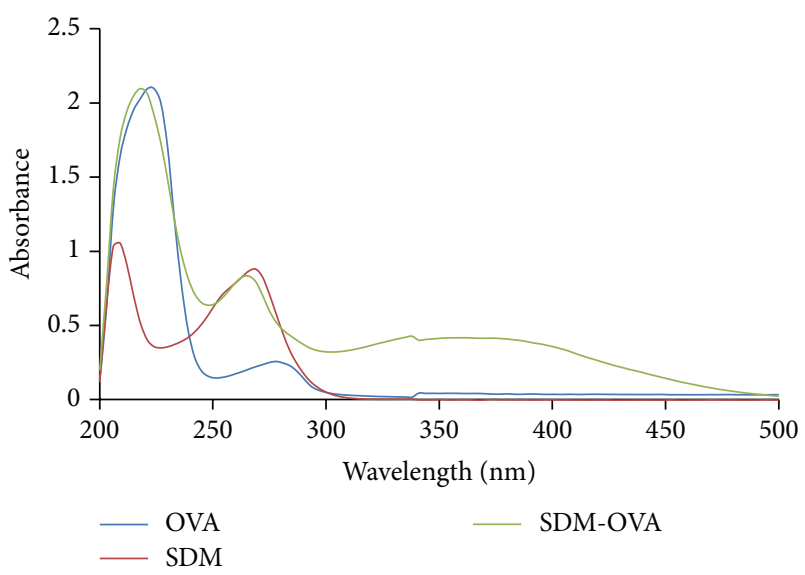

FIGURE 1: UV-vis spectrum of SDM-OVA conjugate.

and hoogenized. To each $2 \mathrm{~g}$ sample, certain SDM standard solution $(0.1 \mathrm{mg} / \mathrm{mL})$ was added to obtain SDM spiked samples. After standing for $30 \mathrm{~min}$, the spiked samples were homogenized with $5 \mathrm{~mL}$ PBS ( $\mathrm{pH} 9.0,0.01 \mathrm{M})$ at $10000 \mathrm{rpm}$ for $2 \mathrm{~min}$ and then centrifuged at $5000 \mathrm{rpm}$ for $10 \mathrm{~min}$. The supernatants were diluted 1:20 with PBS $(0.01 \mathrm{M}, \mathrm{pH}$ 8.0 ), and $50 \mu \mathrm{L}$ aliquots were added to the microplate wells. Then anti-SDM antibody was added for the immunoreaction. Other steps were the same with the protocol of the above nano-ELISA. Meanwhile, the stocked SDM standard solution were added directly to the buffer extract from the control chicken liver tissue and prepared SDM standards $(0.05-20 \mathrm{ng} / \mathrm{mL})$ containing the sample matrix. These SDM standard solutions also will be utilized for calibration of the nano-ELISA.

\section{Results and Discussion}

3.1. Characterization of SDM-OVA Conjugate. The conjugate of SDM and OVA, as coating antigen, was qualitatively analyzed by comparing the UV-vis spectrum of the SDMOVA with those of OVA and SDM. The SDM-OVA conjugate had two absorption peaks (Figure 1), one of which was $270 \mathrm{~nm}(\lambda \max )$ and also the characteristic absorption peak of SDM. Between $300 \mathrm{~nm}$ and $500 \mathrm{~nm}$, a broad absorption peak was the characteristic absorption peak of diazo. The results demonstrated SDM and OVA were conjugated successfully.

\subsection{Characterization of GNPs and GNPs-IgG-HRP Conjugate.} The initial maximum absorbance peak of the GNPs at $518 \mathrm{~nm}$ was shifted to $530 \mathrm{~nm}$ after conjugated with IgGHRP molecules (Figure 2). This was the phenomenon that the plasma absorbance peak of GNPs increases with the size of GNPs increasing. DLS analysis showed that the hydrate sizes of the GNPs and GNPs-IgG-HRP conjugate were $18 \mathrm{~nm}$ and $36 \mathrm{~nm}$, respectively (Figure 3). After combining IgG-HRP, the conjugate size increased by $18 \mathrm{~nm}$, which was close to the twofold of IgG-HRP size. This size expansion demonstrated that the combination of GNPs and IgG-HRP was compact and stable. It was important to note that the GNPs-IgG-HRP

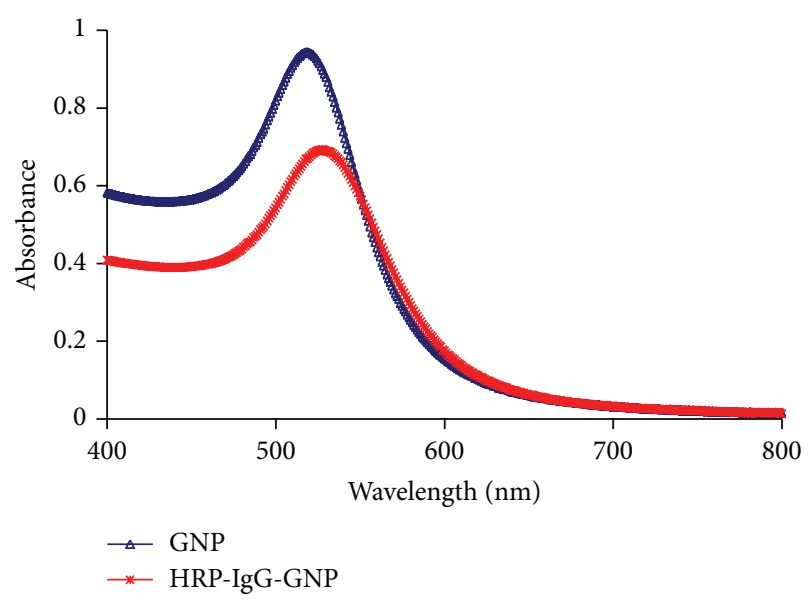

FIgURE 2: UV-vis spectrum of GNP and HRP-IgG-GNP.

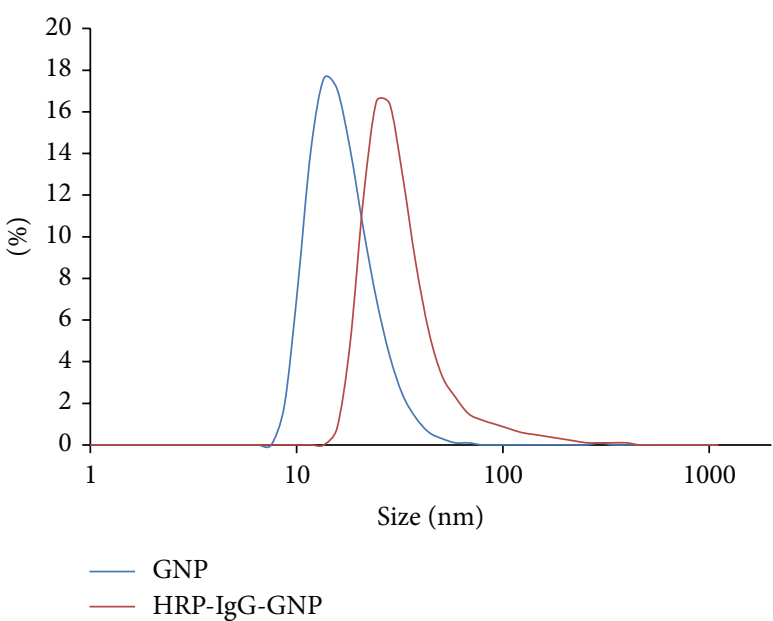

FIgURE 3: Size distributions of GNP and HRP-IgG-GNP.

conjugate was also monodisperse (data not shown), which will contribute to the reproducibility of the GNPs-based ELISA method.

3.3. The Performance of the Nano-ELISA. GNPs with high surface areas offer a possibility to design probes for signal amplification by immobilizing multiple kinds of biomolecules to the surface of GNPs [19, 23]. For application of the GNPs-IgG-HRP conjugate in ELISA method, the concentrations of coating antigen, anti-SDM antibody, and the GNPs-IgG-HRP conjugate have to be screened. Blocking buffer containing proteins or polymers (ovalbumin, gelatin from pork skin, polyvinyl pyrrolidone (PVP, average $\mathrm{mw}$ $40 \mathrm{kDa}$ ), PEG-10000) was compared. Blocking buffer containing gelatin $(0.1 \%)$ output highest signal to noise $(\mathrm{S} / \mathrm{N})$ (data not shown). Under optimized concentrations of coating antigen $(6.0 \mu \mathrm{g} / \mathrm{mL})$, anti-SDM antibody $(2.0 \mu \mathrm{g} / \mathrm{mL})$ and the GNPs-IgG-HRP conjugate (30 fold dilution), the sensitivity (when $A / A_{0} \%$ was $90 \%$ ) could reach $5 \mathrm{pg} / \mathrm{mL}$, which was 20 times more sensitive than that of the traditional ELISA for SDM (Figure 4). The linear range of nano-ELISA was 


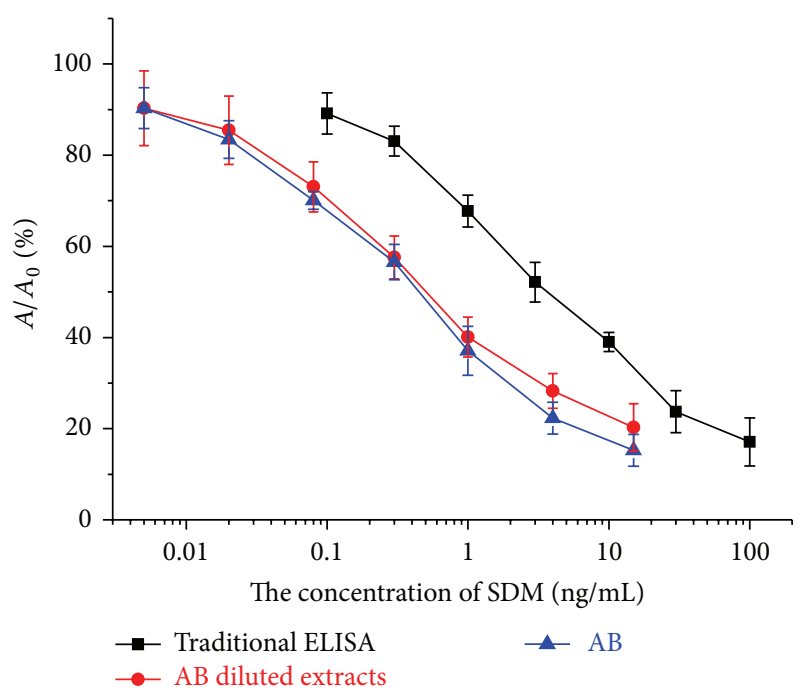

FIgURE 4: Calibration curves for the traditional and nano-ELISA methods for SDM obtained with assay buffer $(\mathrm{AB})$ or with $\mathrm{AB}$ dilution of control liver extracts $(n=4)$.

$0.005 \sim 5 \mathrm{ng} / \mathrm{mL}\left(R^{2}>99 \%\right)$. These results demonstrated that multiple IgG-HRP molecules loading onto the surface of GNPs had rendered the conjugate producing signal amplification function. The signal amplification effect in this method was close to that of other GNPs-based ELISAs for lead ion [19].

This amplification was reasonable, because 20 IgG-HRP molecules, approximated to a sphere of a radius of $5.6 \mathrm{~nm}$, can be bound to the surface of a gold nanoparticle $(15 \mathrm{~nm})$, which was estimated by using the geometrical model of sphere packing around a single central sphere of radius $7.5 \mathrm{~nm}$ (gold nanoparticle) [24]. If IgG-HRP is elongated, more than 20 IgG-HRP molecules will be probably packed on the surface of a gold nanoparticle $(15 \mathrm{~nm})$ [25]. It should be noted that the performance of this GNPs-based ELISA can be improved further through more elaborate design, for example, optimizing the size of GNPs, adopting other kind of bigger nanoparticle, or directly conjugating IgG and HRP to improve the loading of HRP molecules per GNP.

3.4. Validation of the Nano-ELISA. To investigate the performance of this nano-ELISA method for real samples, pretreated control chicken liver tissues were utilized to prepare SDM standard solutions and first tested by this method. It showed that the matrix effect can be eliminated almost completely after 20 -fold dilution and the standard curve obtained using this diluted matrix control was almost identical to the curve obtained using assay buffer $(A B)$ alone (Figure 4).

The spiked chicken liver tissues were tested by the established sample pretreatment protocol. The limits of detection (LOD) for SDM in chicken liver were calculated by taking the mean value of 10 blank samples plus 3 times standard deviations of the mean value and found to be $0.2 \mu \mathrm{g} / \mathrm{kg}$. The chicken liver samples were spiked with 1,6 ,
TABLE 1: Recovery of SDM in chicken liver detected by nano-ELISA $(n=4)$.

\begin{tabular}{lccc}
\hline $\begin{array}{l}\text { Spiked } \\
\text { concentration } \\
(\mu \mathrm{g} / \mathrm{kg})\end{array}$ & $\begin{array}{c}\text { Results } \\
\text { measured } \\
(\mu \mathrm{g} / \mathrm{kg})\end{array}$ & Recovery $(\%)$ & $\begin{array}{c}\text { Relative } \\
\text { derivation } \\
(\%)\end{array}$ \\
\hline 1.0 & $0.837 \pm 0.076$ & 83.7 & 9.3 \\
6.0 & $5.71 \pm 0.34$ & 95.2 & 6.1 \\
40 & $36.15 \pm 3.25$ & 90.3 & 9.0 \\
\hline
\end{tabular}

and $40 \mu \mathrm{g} / \mathrm{kg} \mathrm{SDM}$, respectively, and extracted as mentioned before. The detection recoveries were between $83.7 \%$ and 95.2\% (Table 1) when SDM spiked concentrations were from $1 \mu \mathrm{g} / \mathrm{kg}$ to $40 \mu \mathrm{g} / \mathrm{kg}$ and the extracts were diluted $1: 20$, which demonstrated that this nano-ELISA was reliable for SDM residue detecting in chicken liver.

\section{Conclusions}

In this work, stable conjugate was obtained by facile preparation of GNPs-IgG-HRP conjugate. Appling this conjugate as probe in traditional ELISA, we developed a nano-ELISA method and achieved a highly sensitive detection of SDM in chicken liver tissues. Comparing to traditional ELISA, this nano-ELISA remains simple protocol but is 20 times more sensitive than the later. This novel nano-ELISA method will be useful in screening detection of SDM in animal food and also can be extended to develop detecting methods for other low-molecular weight molecules.

\section{Acknowledgments}

The authors gratefully acknowledge the financial support by the National Natural Science Foundation of China (31371767), the 12th Five Years Key Programs (2012BAK08B01), the Research Program of State Key Laboratory of Food Science and Technology, Jiangnan University (SKLF- ZZA-201202) and the foundation for the Author of National Excellent Doctoral Dissertation of China (201187), and the fund from MOST (201210127).

\section{References}

[1] M. T. Muldoon, S. A. Buckley, S. S. Deshpande, C. K. Holtzapple, R. C. Beier, and L. H. Stanker, "Development of a monoclonal antibody-based cELISA for the analysis of sulfadimethoxine. 2. Evaluation of rapid extraction methods and implications for the analysis of incurred residues in chicken liver tissue," Journal of Agricultural and Food Chemistry, vol. 48, no. 2, pp. 545-550, 2000.

[2] G. Pang, Y. Cao, J. Zhang et al., "Simultaneous Determination of 16 Sulfonamides in Poultry Meat by High-Performance Liquid Chromatography- Tandem Mass Spectrometry," Chinese Journal of Analytical Chemistry, vol. 33, no. 9, pp. 1252-1256, 2005.

[3] S. B. Clark, S. B. Turnipseed, M. R. Madson, J. A. Hurlbut, L. R. Kuck, and J. N. Sofos, "Confirmation of sulfamethazine, sulfathiazole, and sulfadimethoxine residues in condensed milk and soft-cheese products by liquid chromatography/tandem 
mass spectrometry," Journal of AOAC International, vol. 88, no. 3, pp. 736-743, 2005.

[4] Z.-H. Wang, S.-X. Zhang, J.-Z. Shen, and A. E. Sergei, "Analysis of sulfamethazine by fluorescence polarization immunoassay," Chinese Journal of Analytical Chemistry, vol. 35, no. 6, pp. 819824, 2007.

[5] J. Tso, S. Dutta, S. Inamdar, and D. S. Aga, "Simultaneous analysis of free and conjugated estrogens, sulfonamides, and tetracyclines in runoff water and soils using solid-phase extraction and liquid chromatography-tandem mass spectrometry," Journal of Agricultural and Food Chemistry, vol. 59, no. 6, pp. 2213-2222, 2011.

[6] K. Kishida, K. Nishinari, and N. Furusawa, "Liquid chromatographic determination of sulfamonomethoxine, sulfadimethoxine, and their N4-acetyl metabolites in chicken plasma," Chromatographia, vol. 61, no. 1-2, pp. 81-84, 2005.

[7] N. Furusawa, "Organic solvents-free technique for determining sulfadimethoxine and its metabolites in chicken meat," Journal of Chromatography A, vol. 1172, no. 1, pp. 92-95, 2007.

[8] N. Furusawa, "Rapid high-performance liquid chromatographic determining technique of sulfamonomethoxine, sulfadimethoxine, and sulfaquinoxaline in eggs without use of organic solvents," Analytica Chimica Acta, vol. 481, no. 2, pp. 255-259, 2003.

[9] M. Franek, I. Diblikova, I. Cernoch, M. Vass, and K. Hruska, "Broad-specificity immunoassays for sulfonamide detection: immunochemical strategy for generic antibodies and competitors," Analytical Chemistry, vol. 78, no. 5, pp. 1559-1567, 2006.

[10] H. Font, J. Adrian, R. Galve et al., "Immunochemical assays for direct sulfonamide antibiotic detection in milk and hair samples using antibody derivatized magnetic nanoparticles," Journal of Agricultural and Food Chemistry, vol. 56, no. 3, pp. 736-743, 2008.

[11] J. Adrian, H. Font, J.-M. Diserens, F. Sánchez-Baeza, and M.-P. Marco, "Generation of broad specificity antibodies for sulfonamide antibiotics and development of an enzyme-linked immunosorbent assay (ELISA) for the analysis of milk samples," Journal of Agricultural and Food Chemistry, vol. 57, no. 2, pp. 385-394, 2009.

[12] J. Jiang, Z. Wang, H. Zhang, X. Zhang, X. Liu, and S. Wang, "Monoclonal antibody-based ELISA and colloidal gold immunoassay for detecting 19-nortestosterone residue in animal tissues," Journal of Agricultural and Food Chemistry, vol. 59, no. 18, pp. 9763-9769, 2011.

[13] N. Liu, Z. Han, L. Lu et al., "Development of a new rabbit monoclonal antibody and its based competitive indirect enzyme-linked immunosorbent assay for rapid detection of sulfonamides," Journal of the Science of Food and Agriculture, vol. 93, no. 3, pp. 667-673, 2013.

[14] G. Cui, H. Chu, Y. Hu, and C. Xu, "Ultrasensitive signal amplified immunoassay of medroxyprogesterone acetate (MPA) using the atomic absorption of silver deposited on the surface of gold nanoparticles," Food and Agricultural Immunology, vol. 21, no. 2, pp. 165-173, 2010.

[15] C.-F. Peng, Y.-W. Chen, H.-Q. Chen, C.-L. Xu, and Z.-Y. Jin, "A rapid and sensitive enzyme-linked immunosorbent assay (ELISA) method and validation for progestogen multi-residues in feed," Journal of Animal and Feed Sciences, vol. 17, no. 3, pp. 434-441, 2008.

[16] C.-F. Peng, Y.-W. Chen, W. Chen, C.-L. Xu, J.-M. Kim, and Z.-Y. Jin, "Development of a sensitive heterologous ELISA method for analysis of acetylgestagen residues in animal fat," Food Chemistry, vol. 109, no. 3, pp. 647-653, 2008.

[17] S. Bi, Y. Yan, X. Yang, and S. Zhang, "Gold nanolabels for new enhanced chemiluminescence imniunoassay of alphafetoprotein based on magnetic beads," Chemistry, vol. 15, no. 18, pp. 4704-4709, 2009.

[18] C.-H. Yeh, C.-Y. Hung, T. C. Chang, H.-P. Lin, and Y.-C. Lin, "An immunoassay using antibody-gold nanoparticle conjugate, silver enhancement and flatbed scanner," Microfluidics and Nanofluidics, vol. 6, no. 1, pp. 85-91, 2009.

[19] Y. Zhou, X.-L. Tian, Y.-S. Li et al., "A versatile and highly sensitive probe for $\mathrm{Hg}(\mathrm{II}), \mathrm{Pb}(\mathrm{II})$ and $\mathrm{Cd}(\mathrm{II})$ detection individually and totally in water samples," Biosensors and Bioelectronics, vol. 30, no. 1, pp. 310-314, 2011.

[20] Z. Mei, H. Chu, W. Chen et al., "Ultrasensitive one-step rapid visual detection of bisphenol A in water samples by label-free aptasensor," Biosensors and Bioelectronics, vol. 391, no. 1, pp. 2630, 2013.

[21] H. Kuang, X. Chen, C. Hao, W. Ma, L. Xu, and C. Xu, "Immunodriven plasmonic oligomer sensor for the ultrasensitive detection of antibiotics," RSC Advances, vol. 3, no. 38, pp. 1729417299, 2013.

[22] A. Ambrosi, F. Airò, and A. Merkoçi, "Enhanced gold nanoparticle based ELISA for a breast cancer biomarker," Analytical Chemistry, vol. 82, no. 3, pp. 1151-1156, 2010.

[23] C.-P. Jia, X.-Q. Zhong, B. Hua et al., "Nano-ELISA for highly sensitive protein detection," Biosensors and Bioelectronics, vol. 24, no. 9, pp. 2836-2841, 2009.

[24] A. Ambrosi, M. T. Castañeda, A. J. Killard, M. R. Smyth, S. Alegret, and A. Merkoçi, "Double-codified gold nanolabels for enhanced immunoanalysis," Analytical Chemistry, vol. 79, no. 14, pp. 5232-5240, 2007.

[25] H. Jans, X. Liu, L. Austin, G. Maes, and Q. Huo, "Dynamic light scattering as a powerful tool for gold nanoparticle bioconjugation and biomolecular binding studies," Analytical Chemistry, vol. 81, no. 22, pp. 9425-9432, 2009. 

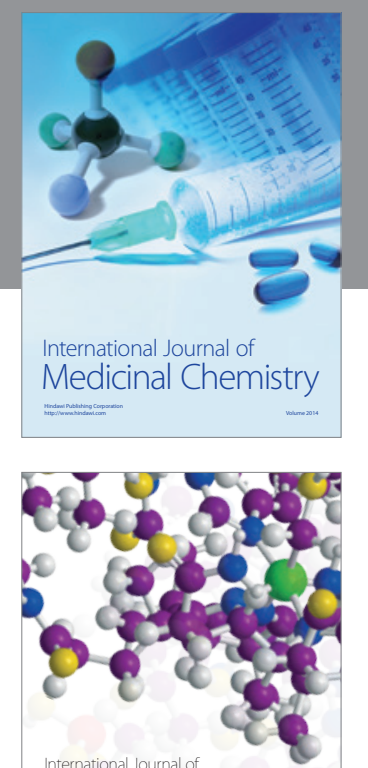

\section{Carbohydrate} Chemistry

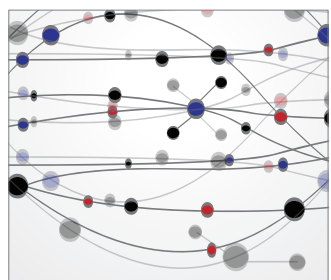

The Scientific World Journal
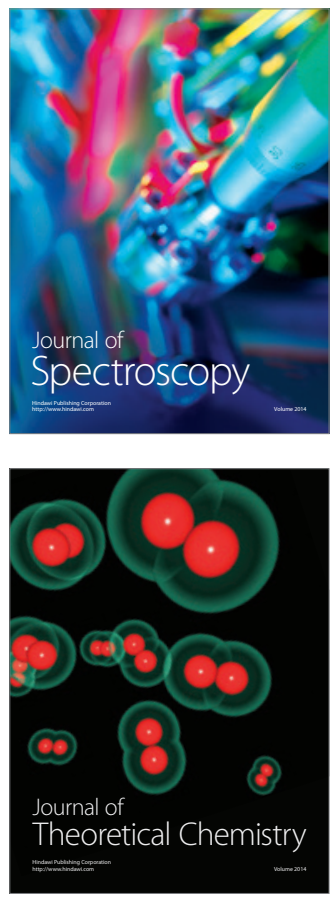
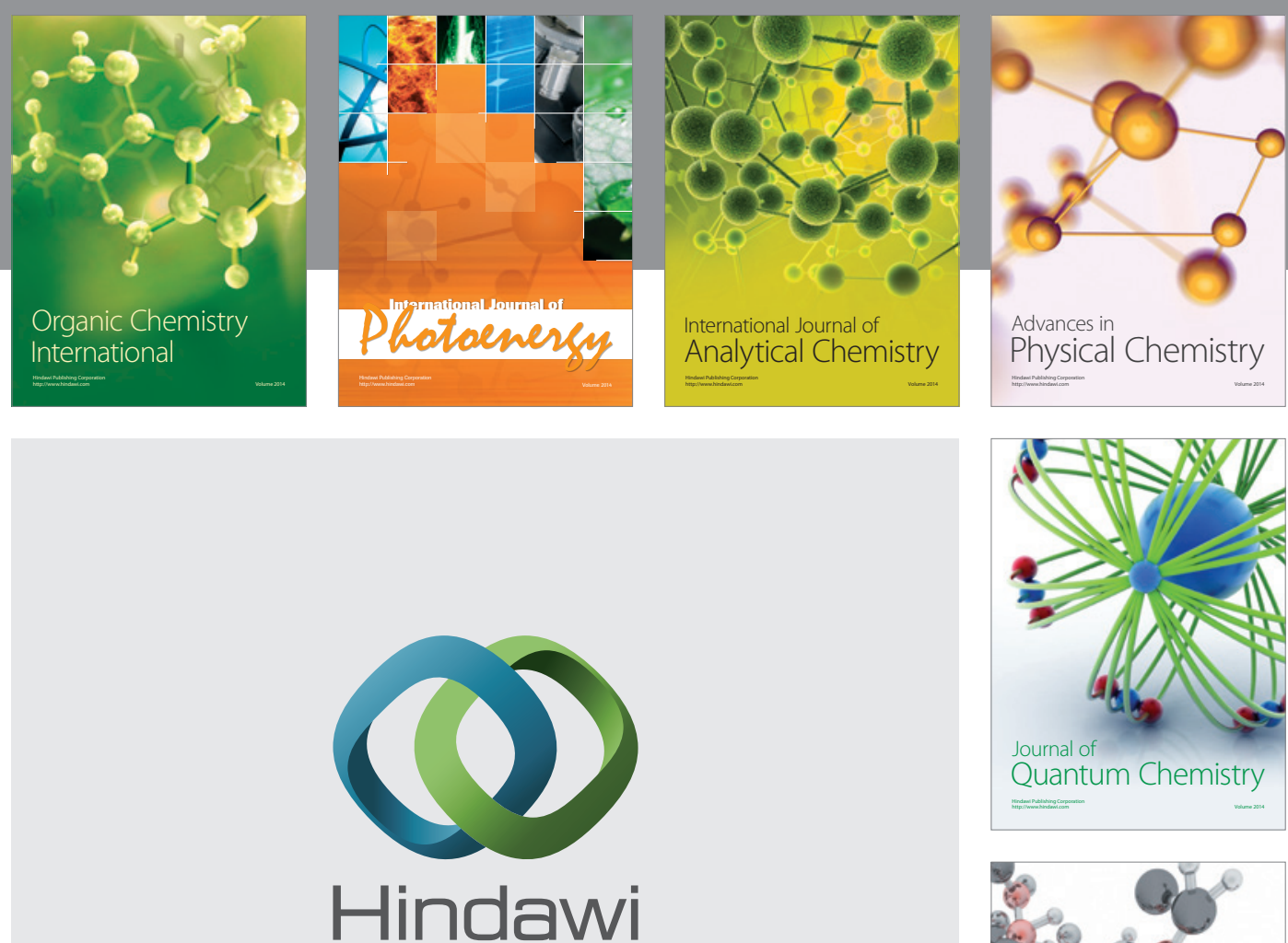

Submit your manuscripts at

http://www.hindawi.com

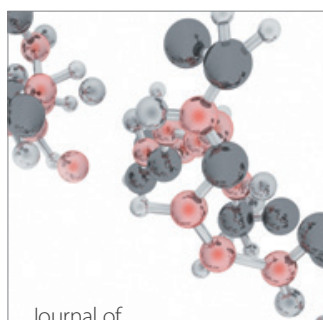

Analytical Methods

in Chemistry

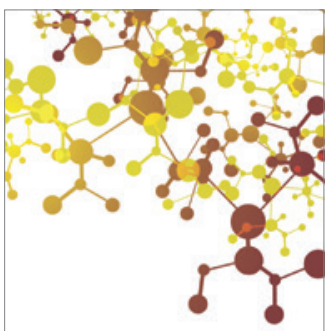

Journal of

Applied Chemistry

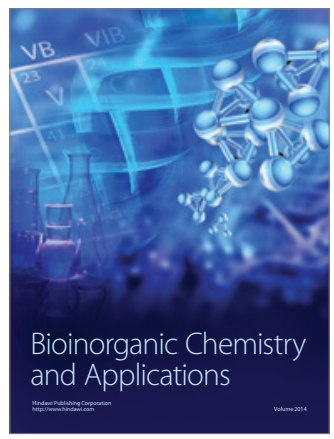

Inorganic Chemistry
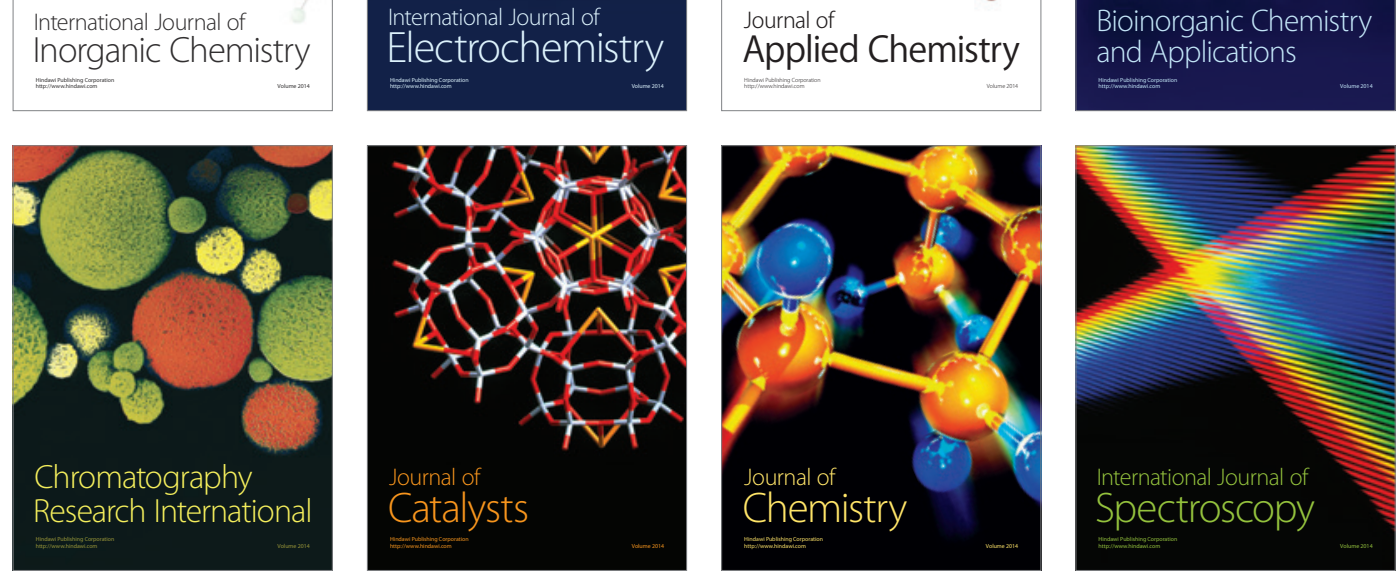